
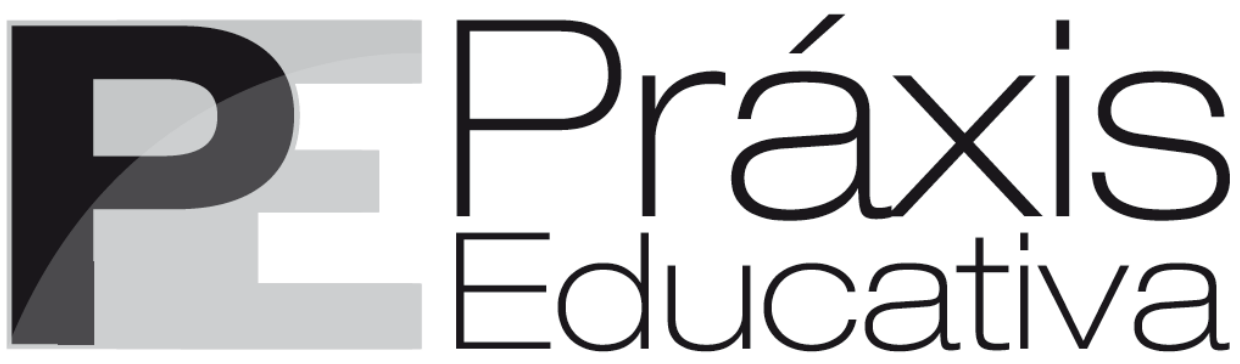

ISSN 1809-4309 (Versão online)

DOI: 10.5212/PraxEduc.v.11i3.0022

\title{
Possibilidades e limites da formação do professor de Arte e da educação artística escolar na perspectiva de humanização
}

\section{Possibilities and limits of Art teacher education and school artistic education from the humanizing perspective}

\section{Posibilidades y límites de la formación del profesor de Arte y de la educación artística escolar en la perspectiva de humanización}

Maria José Dozza Subtil

\begin{abstract}
Resumo: Este artigo apresenta reflexões sobre formação inicial de professores de Arte, conhecimentos priorizados no currículo e demandas da prática artística escolar, resultantes de uma pesquisa realizada com professores da Rede Pública Estadual, egressos em especial das Licenciaturas de Música. São abordadas questões sobre a formação na Licenciatura - prática musical, estudos pedagógicos, estágio e relação com a escola, pontos fortes e fracos do currículo e a prática artística escolar - planejamento, conteúdos e metodologias, demandas dos alunos e dos gestores para as aulas de Arte. O objetivo dessa análise foi cotejar a formação dos professores com as demandas da escola, para discutir os desafios do trabalho docente em Arte/Música com relação aos diferentes determinantes que o constituem. Entre outros problemas, os dados mostram as dificuldades dos docentes em planejar a partir das determinações das Diretrizes Curriculares Estaduais - DCE (2009), que propõem atuação com todas as áreas artísticas (Música, Teatro, Dança e Artes Visuais) e a prática efetiva tendo em vista a formação específica nas Licenciaturas de Música e de Artes Visuais. As respostas permitiram problematizar a relação teoria e prática da formação/trabalho desses professores e apontaram para a contradição entre a educação artística como atividade pragmática e a potencialidade da formação estética e humanizadora apregoada pela perspectiva marxista.
\end{abstract}

Palavras-chave: Licenciaturas em Arte. Formação de professores. Currículo. Prática artística escolar.

Abstract: This paper presents reflections on initial education of Art teachers, prioritized knowledge in the curriculum and demands of school artistic practice, resulting from research performed with teachers from Parana State Public Network (Brazil), especially graduates with Music Teaching Degrees. Questions on education in Teaching Degrees are addressed - musical practice, pedagogical studies, training and relationship with the school, strengths and weaknesses of the curriculum and school artistic practice - planning, content and methodologies, demands of students and managers for Art classes. The purpose of this analysis was to collate education by teachers whilst adhering to school's demands, to discuss the challenges of teaching work in Art/Music in relation to different determinants that constitute it. Among other problems, data shows the difficulties for teachers in planning from the determinations of the Diretrizes Curriculares Estaduais - DCE (2009) (State Curricular Guidelines), which proposes actions within all artistic fields

* Professora da Universidade Estadual de Ponta Grossa (UEPG). E-mail: <mjsubtil@hotmail.com>.

Práxis Educativa, Ponta Grossa, p. 897-916, v. 11, n. 3, set./dez. 2016 Disponível em: <http://www.revistas2.uepg.br/index.php/praxiseducativa> 
(Music, Theater, Dance and Visual Arts) and the effective practice with a view to the specific education in Music and Visual Arts Teaching Degrees. The resulting answers enabled problematization of the relationship between theory and practice of education/work of these teachers and pointed to the contradiction between artistic education as a pragmatic activity and the potentiality of aesthetic and humanizing education proclaimed by the Marxist perspective.

Keywords: Art Teaching Degree. Teacher education. Curriculum. School artistic practice.

Resumen: El artículo presenta reflexiones sobre la formación inicial de profesores de Arte, conocimientos priorizados en el currículum y demandas de la práctica artística en la escuela, como resultados de una investigación realizada con profesores de la red pública estatal, egresados en especial de la Licenciatura en Música. Son abordadas cuestiones sobre la formación en licenciatura - práctica musical, estudios pedagógicos y relación con la escuela, puntos fuertes y débiles del currículum y la práctica artística en la escuela - planeamiento, contenidos y metodologías, demandas de los alumnos y de los gestores para las clases de Arte. El objetivo de ese análisis fue comparar la formación de los profesores con las demandas de la escuela, para discutir los desafíos del trabajo docente en Arte/Música relacionado a los diferentes determinantes que lo constituyen. Entre otros problemas, los datos revelan las dificultades de los docentes con el planear desde las determinaciones de las Directrices Curriculares Estaduales - DCE (2009), que proponen actuación con todas las áreas artísticas (Música, Teatro, Danza y Artes Visuales) y la práctica efectiva considerando la formación específica en las Licenciaturas de Música y de Artes Visuales. Las respuestas permitieron problematizar la relación teoría y práctica de la formación/trabajo de esos profesores y apuntaron para la contradicción entre educación artística como actividad pragmática y la potencialidad de la formación estética y de humanizan difundida por la perspectiva marxista.

Palabras-clave: Licenciaturas en Arte. Formación de profesores. Currículum. Práctica artística en la escuela.

\section{Introdução}

O foco deste artigo é a formação dos professores de Arte para atuação na Escola Básica. Os dados empíricos que o embasam foram coletados com egressos das Licenciaturas em Música e em menor número de Artes Visuais (AV), majoritariamente oriundos dos cursos da Universidade Estadual de Ponta Grossa (UEPG) na cidade de Ponta Grossa, no Estado do Paraná. Buscou-se refletir sobre as práticas curriculares (nas Licenciaturas) e as decorrências para o trabalho docente (na escola) especialmente no que tange ao ensino de Música ${ }^{1}$.

A contingência deste debate decorre de determinantes legais que se cruzam e se contrapõem: a obrigatoriedade da Música na escola estabelecida pela Lei ${ }^{\circ} 11.769$ (BRASIL, 2008), a formação específica em AV e Música propostas nas Licenciaturas, decorrentes dos debates ocorridos nessas áreas nos anos 2000 e as Diretrizes Curriculares Estaduais (DCE) (PARANÁ, 2009), que instituem os conteúdos para as quatro linguagens (Música, Teatro, Dança e Artes Visuais). Ressalta-se que as Diretrizes não obrigam o professor (específico pela formação) a trabalhar com todos esses conteúdos, mas recomenda que ele o faça a partir da sua formação (PARANÁ, 2009). No entanto, o documento desconsidera essa singularidade nos concursos para "professor de Arte" no Estado. Na escola, em decorrência, o planejamento coordenado pela gestão estabelece um bimestre para cada área.

Mesmo que se questione essa "polivalência" implícita nas DCE, é necessário pontuar que a formação nas Licenciaturas em seu afã de abordar apenas os conteúdos de cada área não

\footnotetext{
1 As reflexões deste texto resultam do processo de coleta e análise parcial de dados para o projeto de pesquisa submetido à Bolsa Pesquisador Sênior - Fundação Araucária/2013 intitulado: Políticas, currículos e práticas na formação de professores de artes no Estado do Paraná - reflexões a partir de estudos da realidade das Licenciaturas.
}

Práxis Educativa, Ponta Grossa, p. 897-916, v. 11, n. 3, set./dez. 2016 Disponível em: <http://www.revistas2.uepg.br/index.php/praxiseducativa > 
contempla o universal do qual todas as áreas da Arte se alimentam e se constituem: história, sociologia, política, conhecimentos culturais gerais, que são produzidos na sociedade e que são escamoteados em nome do "específico".

Desse modo, os desafios dos professores de Arte são revelados nas interpretações que eles apresentam sobre sua formação em relação às exigências da prática escolar, conteúdos de ensino, metodologias, percepções sobre a gestão escolar, planejamentos e DCE, etc., e evidenciam-se, também, nos dados coletados que ora são apresentados. Vale ressaltar as visões dicotômicas, contraditórias, às vezes pouco embasadas e confusas que os professores revelam. Salvo exceções, há dificuldades em traduzir quais os conteúdos e as metodologias adequados à realidade dos graus de ensino onde atuam: anos finais do Ensino Fundamental e Ensino Médio (alunos adolescentes e jovens).

A pesquisa envolveu 16 professores de AV e Música da cidade de Ponta Grossa que aceitaram responder às questões sobre a formação na Licenciatura na relação com a prática artística escolar. $O$ universo é assim constituído: 11 egressos do sexo feminino e 5 do masculino; 11 de Música e 5 de Artes Visuais; 11 cursaram as Licenciaturas da UEPG e 4 vieram de outras universidades. Dos egressos de Música, 7 formaram-se no Currículo de 2003 e 4 no currículo de 2008 da Licenciatura em Música da UEPG ${ }^{2}$; 9 são Pós-Graduados em cursos afins³.

$\mathrm{Na}$ primeira parte, apresentam-se fundamentos teóricos sobre formação e trabalho docente na sociedade capitalista. Na segunda, trata-se das manifestações referentes à formação dos professores no cotejamento com as demandas da escola. Na terceira parte, discutem-se os desafios da prática em relação aos diferentes determinantes que a compõe. Transversalizando os dados coletados, apresentam-se teorizações atinentes tanto aos debates sobre Arte quanto sobre formação inicial e continuada no tangenciamento com as necessidades da prática escolar.

\section{Fundamentos sobre formação e trabalho docente na sociedade capitalista - as decorrências para o ensino de Arte}

Um pressuposto da expansão do capitalismo contemporâneo é a submissão de todos os aspectos da sociabilidade - cultura, política, educação em especial - às demandas do mercado globalizado e à acumulação de capital. A economia como materialidade dominante na sociedade escamoteia as "amarras" humanitárias e culturais na busca da eficiência do processo educacional. Nesse contexto, formação e trabalho docente são práticas que dependem diretamente do que é priorizado pelos organismos nacionais e internacionais para a educação e a cultura como insumos do desenvolvimento econômico e da acumulação do capital.

A submissão do complexo educacional aos imperativos da acumulação capitalista traduzse nas determinações legais para a formação de professores da Educação Básica por meio da pedagogia das competências necessárias às demandas do mercado e do mundo do trabalho tecnificado na fase atual do capitalismo globalizado. Segundo Trevisan (2011), tal enfoque

\footnotetext{
2 As Licenciaturas de Música e Artes Visuais da UEPG foram instituídas no ano de 2003 (UEPG, 2003), como formação que privilegiava a abrangência do campo do ensino da Arte - sem cair na "polivalência" - e a inter-relação dos saberes estabelecendo pontos de integração entre as diferentes linguagens. A proposta previa um currículo articulado, na forma de Eixos Temáticos e Núcleos de Conhecimentos (NC) que, em alguns momentos, trabalhava com conteúdos básicos de Música e Artes Visuais para os alunos dos dois cursos (SUBTIL, 2003, 2004). Esse currículo foi totalmente modificado na reformulação de 2008 (UEPG, 2008), quando cada curso assumiu sua especificidade e foi totalmente abandonada qualquer relação entre eles.

3 Ressaltamos que essas especializações, quando nomeadas pelos egressos de Música, são prioritariamente relacionadas a outras áreas: Música Teatro, Dança e Artes Visuais.
}

Práxis Educativa, Ponta Grossa, p. 897-916, v. 11, n. 3, set./dez. 2016 Disponível em: <http://www.revistas2.uepg.br/index.php/praxiseducativa> 
inscreve-se em uma visão instrumental, técnica e pragmatista que considera mais o treinamento e a adaptação e menos contradições inerentes tanto à formação quanto à atuação docente.

A gênese da Arte, ligada ao relativo antagonismo em relação ao mundo produtivo ${ }^{4}$, explica, em parte, o dilema com que se depara essa área no interior da escola, em que prevalecem as disciplinas pragmáticas, úteis ao trabalho e à empregabilidade no capitalismo contemporâneo.

Refletir sobre a dimensão ontológica da Arte supõe considerar que ela resulta de um dado momento do desenvolvimento histórico social do homem, ou seja, "[...] houve necessidade de ócio para que o trabalho artístico se desenvolvesse como uma criação humana consciente [...]" (MAGALHÃES, 2015, p. 104). Isso explica, relativamente, o tardio aparecimento do reflexo estético em comparação ao trabalho. "[...] o estético pressupõe materialmente uma determinada altura da técnica e, além disso, um ócio para a criação de superficialidade, determinada pelo aumento das forças produtivas do trabalho" (LUKÁCS, 1966/67 apud MAGALHÃES, 2015, p. 104). Para Lukács (1970), o papel da Arte está relacionado ao da autoconstrução do gênero humano. Magalhães $(2015$, p. 102) afirma que a obra de Arte potencializa a capacidade humana de resgatar o passado com antecipações de futuro, "[...] capacidade ímpar do ser humano que permite a criação do novo [...]”.

As propostas legais, grosso modo, mesmo quando pretendem avançar com a obrigatoriedade da Arte no currículo, propondo formação específica para professores e concursos de ingresso, afirmam, no cotidiano, mais o viés utilitarista da educação artística do que propriamente a prática de Arte como humanização e formação estética. Isso aparece de forma clara nas percepções dos sujeitos das escolas sobre formação, atuação e requerimentos para o ensino de Arte.

Como visto nas falas, os conteúdos e as metodologias aprendidos e "aplicados", de modo geral, pouco têm a ver com a formação estética e com um trabalho criador e significativo em Arte. Prevalece uma forma reducionista, embasada no desenvolvimento de competências mais técnicas do que estéticas. No entanto, não se pode desconsiderar o esforço dos professores investigados em buscar alternativas que supram as lacunas da formação e procurar o caminho mais adequado, dadas as circunstâncias da prática, para a educação artística dos alunos.

Em O Capital, Marx (1983) faz do trabalho, intercâmbio com a natureza que produz a humanidade do homem, o momento fundante do ser social e estabelece a distinção com o trabalho abstrato, assalariado, alienado pelo capital ao produzir mais-valia. ${ }^{5}$ Lessa $(2012$, p. 28) considera que: "O trabalho abstrato é a redução da capacidade produtiva humana a uma mercadoria, a força de trabalho, cujo preço é o salário". O autor estabelece a diferença com o trabalho na dimensão ontológica que é "[...] o complexo que cumpre a função social de realizar o intercâmbio material do homem com a natureza, é o conjunto de relações sociais encarregado da reprodução da base material da sociedade" (LESSA, 2012, p. 28).

Essa diferença que pode ser apropriada no ensino de Arte como atividade docente humanizadora e atividade docente alienada, sujeita às demandas exógenas à formação estética dos

\footnotetext{
4 Vázquez (1978, p. 171) tece considerações quanto a essa questão: "Marx se ocupa repetidamente, ao longo de sua obra, das relações entre arte e capitalismo. Como o estético, em geral, é para ele uma esfera essencial da existência humana, não pode deixar de lhe preocupar o destino da arte, enquanto manifestação das forças criadoras do homem, na sociedade capitalista. Uma vez rasgado o véu que oculta a substância exploradora da produção industrial sob o capitalismo, Marx assinala que esta produção "é hostil a certas produções de tipo artístico, tais como a arte e a poesia"”.

${ }^{5}$ Sergio Lessa propõe uma leitura esclarecedora de Marx pela mediação da Ontologia do ser social de Lukács sobre trabalho em especial no livro $O$ mundo dos homens: trabalho e ser social.
}

Práxis Educativa, Ponta Grossa, p. 897-916, v. 11, n. 3, set./dez. 2016 Disponível em: <http://www.revistas2.uepg.br/index.php/praxiseducativa $>$ 
alunos, é evidenciada nas manifestações dos professores. Eles revelam as dificuldades da prática artística pela necessidade de submissão de uma área intuitiva, criativa (humanizadora) que necessita de tempo e espaço adequados a sua efetivação, à racionalidade da atividade educacional assalariada no contexto político e econômico neoliberal com suas demandas utilitárias e pragmáticas (SUBTIL, 2014).

É importante afirmar que isso significa a necessidade de ir além do que se convencionou chamar educação artística escolar, para pensar essa prática na universalidade do conceito de Arte, cuja função precípua é desvelar a realidade humano social e proporcionar experiências estéticas significativas. A ideia de "artes" ou "linguagens artísticas" refere-se às manifestações musicais, visuais, cinestésicas, teatrais, que possuem validade em suas especificidades teóricometodológicas nas relações escolares. No entanto, afirma-se a necessidade de retomar o campo mais abrangente do conceito (Arte), dada a sua complexidade como área de conhecimento humano que envolve o sensível e a técnica, a razão e a intuição.

O desafio que se coloca para os professores de Arte/Música é considerar, no ensino, tanto o contexto histórico da Arte na particularidade dos estilos e das formas, quanto os conceitos e as técnicas singulares que possibilitam o usufruto e a produção artística em seu caráter de universalidade genérica.

\section{O que os sujeitos manifestam sobre a formação, o trabalho docente e as demandas da realidade $^{6}$}

\section{Visões sobre a formação proposta pelas Licenciaturas - desafios para a atuação docente}

Pereira (2013) constata, nos currículos das Licenciaturas de Música, a prevalência do "saber conservatorial" que privilegia uma tradição técnica musical em detrimento de conhecimentos contextuais (da cultura contemporânea) e pedagógicos (das demandas escolares). Esse autor trabalha com o conceito de habitus conservatorial próprio do campo artístico transposto ao educativo na inter-relação estabelecida entre esses dois campos. Isso se objetiva nos projetos pedagógicos das Licenciaturas onde aparece um bloco de disciplinas não passíveis de discussão já que seria "natural" que compusessem a grade. Para ele, essa é a consolidação de uma forma conservatorial na formação do "músico professor" com caráter essencialmente técnico, estético, artístico e profissional, com forte apelo à performance musical. Subtil (2015, p. 180) afirma que não se pode desqualificar esse conhecimento historicamente instituído, já que o clássico é o que permanece e que resiste ao tempo. No entanto, a autora ressalva a necessidade de contextualizar esses saberes "[...] na relação com a música da indústria cultural e com as demandas da sociedade e da escola para o ensino de arte/música" na perspectiva de promover uma formação estética.

Em relação à formação que receberam na Licenciatura, os entrevistados dividem-se nas avaliações positivas e/ou negativas, mas prevalece a crítica à insuficiente relação do curso com a prática da escola. Para eles, a formação docente acontece na prática, porque a Licenciatura "não dá conta de tudo". Alguns professores não reclamam da formação recebida e delegam a si mesmos a tarefa de educarem-se por meio de diferentes estratégias, tais como vídeos, leituras,

\footnotetext{
6 A partir deste item, são apresentados, além dos dados coletados especialmente para este artigo, também as reflexões embasadas em pesquisas de Subtil (2009, 2014, 2015), que mostram como a maioria das manifestações se repete há anos sobre ensino de Arte na escola. Por esse motivo, optamos por apresentar uma somatória geral das falas e algumas manifestações que consideramos emblemáticas. Assim sendo, os 16 sujeitos investigados, embora não signifiquem o universo total dos professores de Arte na região dos Campos Gerais, são representativos e permitem uma atualização das concepções vigentes entre os docentes.
}

Práxis Educativa, Ponta Grossa, p. 897-916, v. 11, n. 3, set./dez. 2016 Disponível em: <http://www.revistas2.uepg.br/index.php/praxiseducativa $>$ 
Possibilidades e limites da formação do professor de Arte e da educação artística escolar...

cursos, etc. Há uma ideia de formação continuada ou em serviço, mas como tarefa individual, como prova do "esforço" do professor de Arte para adequar-se à realidade da escola.

\section{Quanto aos conbecimentos musicais ${ }^{7}$}

Sobre a prática musical específica ofertada no curso, há controvérsias: aqueles que acham que o fundamento da Licenciatura é a Música ${ }^{8}$, e não o pedagógico, consideram a prática musical fraca; os que apontam o pedagógico como mais relevante dizem que essa prática é satisfatória. $\mathrm{O}$ que se percebe é a dicotomia de concepções de músico e professor que, na Licenciatura, historicamente são complementares e antagônicas pela sobreposição do pedagógico ao musical. A força de um parece reduzir o outro. ${ }^{9}$

A questão da universalidade do conceito de artista é pouco refletida e, consequentemente, não permite extrair o potencial heurístico desse conceito. Maron Neto (2012, p. 99), partindo da ideia gramsciana de que todo o ser humano é potencialmente intelectual (mesmo que não exerça essa função), afirma que a noção de artista "[...] remete ao indivíduo que, pela sua singularidade, supera a particularidade que originou a produção artística, atingindo a universalidade, o gênero humano, possibilitando a sua emancipação e a dos demais indivíduos". ${ }^{10}$ Apesar de nem todos exercerem a função de artista, é possível que todos exercitem essa potencialidade de humanização que, em nosso entender, está ligada diretamente à educação artística. Assim, o desafio não é separar o artista do professor, mas elevar a capacidade máxima da potência da Arte na docência.

Há manifestações favoráveis à prática musical na disciplina que trabalhava instrumentos musicais no primeiro currículo da Licenciatura em Música da UEPG, de 2003 (UEPG, 2003), especialmente em relação à flauta e ao coral, mas prevalece o termo "razoável" em se tratando da música como um todo ofertada no curso.

Os egressos do segundo currículo, de 2008 (UEPG, 2008), apontam com maior ênfase a formação teórico-musical. Isso se confirma pela retomada da música sem outras áreas artísticas transversalizando o currículo, como era o caso de 2003. De todo modo, o que parece consenso para a maioria dos sujeitos é o questionamento dos conhecimentos musicais "aplicáveis ou não em sala de aula". Nesse sentido, um egresso de Música questionou o fato de que "[...] houve muita exigência nos conhecimentos teórico-musicais [...] para uma prática (escolar) que é em todas as áreas" (exigência do planejamento).

$\mathrm{Na}$ verdade, a pesquisa revela que os conteúdos musicais na formação não são considerados em sua origem social e histórica e apenas adquirem sentido quando respondem a exigências imediatistas da ação na escola. Isso decorre dos limites dos currículos das Licenciaturas que pouco enfocam os determinantes históricos, políticos e sociais, seja da arte em geral seja da

\footnotetext{
${ }^{7}$ Optamos por apresentar neste item as manifestações dos egressos de Música pelo fato de que foram os que mais desenvolveram as respostas nesse quesito.

8 Em pesquisa realizada por Subtil (2011) e em andamento Subtil (2016b), constata-se que alguns licenciandos esolhem a Licenciatura por não haver Bacharelado de instrumentos. Na última pesquisa, também se constata que a pré-formação é mais consistente do que há anos, em termos de tempo de estudo e ênfase na teoria musical.

${ }^{9}$ A pesquisa de Subtil ( 2016b) sobre as percepções dos licenciandos quanto à futura atuação profissional mostra que a maioria dos investigados da Licenciatura em Música não pretende atuar na docência e prefere seguir carreira no campo musical (SUBTIL, 2016b). É o lado artista prevalecendo.

${ }^{10}$ Neste artigo, entendemos, a partir de Lukács (1970), que o movimento dialético da realidade supõe o movimento do singular ao universal e vice-versa sempre mediatizado pelo particular (o contexto histórico).
}

Práxis Educativa, Ponta Grossa, p. 897-916, v. 11, n. 3, set./dez. 2016 Disponível em: <http://www.revistas2.uepg.br/index.php/praxiseducativa $>$ 
música em particular. Somado a isso, têm-se que a ênfase na performance teórico/instrumental de caráter prático é uma característica histórica das Licenciaturas de Música.

\title{
Fundamentos da educação (universalidade) para a formação dos docentes de Arte
}

A exigência de conhecimentos "práticos" que deem conta da imediaticidade da ação docente decorre de uma concepção que apregoa a ênfase nas experiências práticas, tanto na formação quanto na atuação. Moraes (2001) qualifica esse recuo da teoria como corolário dos postulados pós-modernos que desqualifica o embasamento teórico da relação teórica/prática e a devida contextualização histórica dos problemas educacionais.

Algumas falas dos egressos entrevistados consideram os conhecimentos pedagógicos ou a teoria como valores somente no confronto com a prática. Nesse sentido, as visões positivas sobre os conhecimentos didáticos remetem aos fundamentos para a prática, mesmo que com ressalvas:

\begin{abstract}
Muitas questões trabalhadas em disciplinas teóricas, como Didática, foram importantes para ampliar a visão a respeito das diferenças metodológicas e fundamentar as acões em sala de aula. Outras disciplinas contribuíram mais especificamente na parte prática, trazendo algumas ideias de projetos e atividades e formas de desenvolver certos conteúdos. (Egressa de Música).

Em geral, as disciplinas do curso de Licenciatura em Música proporcionaram um aprofundamento nos conceitos musicais que são distantes da realidade educativa da Educação Básica. (Egressa de Música).
\end{abstract}

Isso também reforça a ênfase no musical em detrimento do "pedagógico", que confirma a ideia do saber conservatorial (PEREIRA, 2013). Entretanto, duas manifestações tecem críticas ao acento na formação musical e menos na formação pedagógica ou nos aspectos gerais da educação: "O currículo da minha Licenciatura foi eficiente nas disciplinas da educação voltadas para a educação musical, por exemplo, Fundamentos da Educação Musical" (Egressa de Música). Contudo, ela complementa: "No entanto, as disciplinas da área de educação como Psicologia, Didática etc. deixaram muito a desejar e tudo que aprendi foi em minha prática docente ainda durante a graduação". Outra egressa de Música também afirma: "Senti falta dos aspectos gerais da educaşão na educaşão musical, psicologia da música, sociologia, filosofia".

Note-se que as referências têm sido à educação musical. Não são nomeados nas respostas fundamentos amplos da Educação: História, Sociologia, Filosofia. Essa é uma dimensão da formação dos professores que possui menos peso no currículo dos cursos ${ }^{11}$ e parece explicada pela necessidade premente de dar conta da realidade escolar. É como se esses conhecimentos que são a base da educação e da docência não tivessem o menor peso no confronto com os problemas do cotidiano em sala de aula.

Nesse sentido, tanto na Música quanto nas Artes Visuais, os licenciados que apregoam o fortalecimento dos conteúdos próprios da área artística questionam os conhecimentos históricos, filosóficos e pedagógicos. Por outro lado, mesmo quem afirma a docência como objeto da licenciatura acha que esses fundamentos são menos importantes que os conteúdos "práticos", necessários para dar aulas. Há, entretanto, uma referência ao currículo de 2003 de uma egressa de AV da UEPG quanto ao Eixo Docência em Arte, trabalhado de forma interdisciplinar por

11 Mateiro (2009) apresenta o peso dos conhecimentos nos currículos das Licenciaturas em Música: formação musical - 43\%; formação psicopedagógica específica - 32\%; formação psicopedagógica geral - 9\%; e formação cultural - $2 \%$.

Práxis Educativa, Ponta Grossa, p. 897-916, v. 11, n. 3, set./dez. 2016 Disponível em: <http://www.revistas2.uepg.br/index.php/praxiseducativa $>$ 
professores da área da educação ${ }^{12}$. Segundo ela, "[...] o forte foram os projetos desenvolvidos para a docência, contemplando carga horária satisfatória para cada área de ensino da Arte, estágios e regências em todos os niveis de ensino com a devida reflexão teórica mais ampla".

Outro aspecto levantado quanto ao Currículo de 2003 refere-se à História da Arte e da cultura universal no eixo "Reflexão Artística", que abordava fundamentos históricos e sociológicos mais amplos da Arte e promovia viagens culturais e visitas a museus e exposições (BIENAIS) com os alunos das duas Licenciaturas. Essa prática, segundo a egressa, "[...] provocava uma integração interessante das áreas" (Egressa de AV - UEPG). Como já visto, a formação cultural é um ponto fraco nas Licenciaturas.

\section{Relação teoria (currículo da Licenciatura) e prática (trabalbo docente na escola)}

O conceito de "prática" como espaço de "aplicação" dos conhecimentos do curso é recorrente em todas as falas. Isso denota a ausência de uma reflexão mais abalizada na própria Licenciatura sobre "práxis" como ação transformadora consciente, teleológica e cognoscitiva e de práxis artística (criadora) como o mais alto nível de objetivação humana (VÁZQUEZ, 1986). O reducionismo das visões da relação teoria prática impede a compreensão de que formação inicial e formação continuada são processos sociais, coletivos e que caminham junto ao processo de trabalho (ação humana consciente e social). Sobre isso, é pertinente a queixa da maioria dos egressos quanto "à falta de contato com a realidade escolar". A ideia de conteúdos "práticos" para aplicar na escola aparece também com ressalvas, dada à distância com a realidade da sala de aula:

Algumas disciplinas cursadas me auxiliaram muito em minha prática, tais como História da Música e Teoria e Percepção Musical. Porém disciplinas como Práticas Pedagógicas não foram, em alguns momentos, significantes para minha formação como profissional, uma vez que bá muita diferença entre o que é mostrado pelo professor e a realidade da sala de aula. O professor deveria proporcionar aos acadêmicos uma melhor preparação para as diversas situações que acontecem na docência. (Egresso de Música).

Nessa perspectiva, quanto ao fato da Licenciatura ter ou não preparado para a realidade escolar, há consciência de que nenhuma Licenciatura dá conta das mudanças que ocorrem na escola e há necessidade de formação continuada. Percebe-se que, para dar conta das demandas do ensino, muitos egressos "[...] se viram como podem pedindo auxilio e consultando os professores da área da Música que auxiliavam em práticas possiveis para a atuação" (Egresso de Música). Na verdade, é projeto pessoal interessado nos problemas do dia a dia da sala de aula e das exigências do planejamento bimestral.

Os dilemas da relação teoria-prática são expressos em uma fala que é emblemática: " $A$ realidade é outra. Precisa se aprimorar nesta área. A gente é lançado na sala sem saber até como preencher um livro [...]” (Egresso de Música). Há uma visão generalizada de que a prática musical deve estar totalmente voltada à formação e à capacitação para a sala de sala: "Deve instrumentalizar o professor para os desafios dos variados públicos da Educação Básica” (Egresso de Música). Dessas percepções, o estágio curricular aparece como:

\footnotetext{
${ }^{12}$ Uma professora do Departamento de Educação trabalhou com os fundamentos gerais sobre a formação docente e outra do Departamento de Métodos e Técnicas de Ensino com os conhecimentos didático-pedagógicos do campo do ensino.
}

Práxis Educativa, Ponta Grossa, p. 897-916, v. 11, n. 3, set./dez. 2016 Disponível em: <http://www.revistas2.uepg.br/index.php/praxiseducativa $>$ 
Insuficiente [...]. Inadequado [...]. Seria válido inserir os alunos em vários segmentos culturais e não só em sala de aula [...]. O curso nos deixou na mão, a ajuda foi de colegas e professores [...]. Senti falta de material e recursos que dessem conta da realidade que enfrentei [...]. Poucas regências, poucas observações [...]. Impossibilidade de fazer um diagnóstico adequado. (Egressos de AV e de Música).

Uma manifestação em particular diz: "As atividades de estágio nas escolas não eram muito estruturadas e, como havia muitos professores fora da área (Português, História etc.), tanto a parte de observação quanto a parte prática ficaram bastante prejudicadas" (Egressa de Música). Se a observação da prática escolar é condição para a atuação, nota-se que o educativo é justamente a negação dessa prática pela não superada presença de professores de outras áreas no ensino de Arte.

Como positivos, são citados os projetos de extensão (Musicalização da UFPR) e o Programa Institucional de Bolsa de Iniciação à Docência - PIBID (UEPG), como instrumentos de aproximação com a realidade escolar em diferentes níveis de escolarização que contribuiriam para a formação docente. Ressalta-se a importância de iniciativas governamentais que tenham esse caráter propositivo na relação da formação com a realidade escolar.

O embate entre os conceitos de artista e professor, já discutido anteriormente, revela-se quando os egressos apresentam como negativo o fato de que a maioria dos professores da Licenciatura em Música são músicos e não possuem experiência pedagógica. Importa ressaltar que esses professores - a maioria - são formados nas duas instituições referenciais para a Arte e seu ensino no Paraná: Escola de Música e Belas Artes do Paraná (EMBAP), historicamente destinada ao bacharelado tanto em Música quanto em AV, e a Faculdade de Artes do Paraná (FAP) - que se dedicou mais à formação de professores, mas iniciou enfatizando a prática instrumental musical ${ }^{13}$. De todo modo, a prevalência do conhecimento musical e das Artes Visuais sobre o pedagógico informa "geneticamente" os docentes das Licenciaturas.

Outro problema é a distância dos professores específicos das áreas artísticas do contexto escolar. Um egresso de AV diz que a relação teoria prática deixou a desejar principalmente porque: "Os professores do curso não têm conhecimento da escola ou vivência em sala de aula, têm visão superficial e teórica da educaşão". Ele considera que: "Os professores têm que saber os estudos e pesquisas sobre os 'possivieis caminhos' que nortearão a educação. O que não pode é haver descompasso entre o debate teórico e a prática". Na mesma perspectiva, há outra manifestação:

Acredito que tanto em questão de currículo quanto em questão de professores o curso de Licenciatura esteve bastante distante da prática. Muitos dos professores que atuam em cursos de Licenciatura da UEPG não têm prática ou conhecimento da escola pública e mesmo os conteídos trabalhados deixam uma lacuna entre teoria/prática. Dessa forma, quando fui atuar como professor, não me sentia preparado para o trabalho. (Egresso de AV).

Quanto aos conbecimentos relativos às outras áreas artísticas - a proposta das DCE

Para discutir esse tema que se constitui no principal desafio da prática docente em Arte no Paraná, como se verá a seguir, é necessário esclarecer que as Diretrizes Curriculares do Paraná propõem uma integração de conhecimentos por meio de eixos (elementos formais, composição, movimentos e períodos) que mantém conteúdos comuns do campo artístico sem perder a

\footnotetext{
13 Subtil (2014) aprofunda reflexões sobre o histórico dessas duas instituições e o impacto sobre a formação dos docentes, em especial de Música.
}

Práxis Educativa, Ponta Grossa, p. 897-916, v. 11, n. 3, set./dez. 2016 Disponível em: <http://www.revistas2.uepg.br/index.php/praxiseducativa > 
singularidade dos conhecimentos específicos (Música, Artes Visuais, Dança e Teatro). A ideia que atravessa as diretrizes é a de que essa "interdisciplinaridade" permite uma superação do reducionismo da polivalência, por afirmar conteúdos e conhecimentos historicamente constituídos de todas as áreas, mantendo em comum eixos teóricos metodológicos (PARANÁ, 2009). Mesmo criticando o ecletismo teórico que informa esse documento, considera-se válida a tentativa de ampliar os domínios dos conhecimentos artísticos para além da especificidade das áreas, remetendo-os aos determinantes mais amplos da sociedade. ${ }^{14}$ Ressalta-se que, na Licenciatura em Música, segundo o professor coordenador de estágio, as DCE são abordadas em seus aspectos teóricos e metodológicos.

Quanto à questão aqui discutida, há dois tipos de manifestação que são emblemáticas. As primeiras afirmam:

\begin{abstract}
A Licenciatura atendeu ao que preciso por me dar outros conbecimentos para além da música [...]. Só fui ver a importância disso quando comecei a lecionar [...]. Foi muito válido ter tido um ano de aula com professores de outras áreas da Arte - noções básicas, mas que me impulsionam a pesquisar mais e trabalhar com embasamento com os alunos [...]. Apesar de muitos colegas acharem que não tem nada a ver (especialmente teatro e dança) afirmo que muito dos conbecimentos adquiridos foram utilizados em sala de aula com os alunos [...]. As aulas de teatro foram relevantes para trabalhar na prática. (Egressos de AV e Música de 2003 - UEPG).
\end{abstract}

Já as segundas manifestações dizem o seguinte: "Senti falta de conhecimentos nas outras áreas e tive que fazer uma especialização"; "A Licenciatura falhou ao não dar as outras áreas e manter distância com a escola” (Egressas de Música 2008). A inclusão desses conteúdos - questionados veementemente pela Associação Brasileira de Educação Musical (ABEM) e pela Federação de Arte Educadores do Brasil (FAEB) - parece estar, particularmente, incorporada na prática dos professores de Música, que até buscam especialização em AV como fator facilitador na lida com os alunos e com a gestão da escola.

Interessante observar que, na prática da escola - que será abordada a seguir - no geral, os questionamentos sobre os encaminhamentos das DCE não são categoricamente criticados. Com apenas uma exceção, há uma espécie de aceitação ao que é proposto para o planejamento anual trabalhar um bimestre para cada área.

\title{
Visões sobre a docência do professor de Arte - dilemas da relação teoria (formação) e prática (exigências da escola)
}

Os desafios da docência revelados têm sempre relação com a formação e com a (in)adequação aos requerimentos do campo de atuação. Como visto anteriormente, de modo geral, não há compreensão da relação dialética teoria/prática como "práxis" transformadora consciente, que leve o aluno à "autoconstrução genérica" (LUKÁCS, 1970), a uma formação estética que permita superar as demandas pragmatistas da sociedade capitalista. Ressalta-se que o professor, tanto quanto os alunos, é sujeito/objeto dessas demandas, seja na formação seja na atuação.

No próximo item, foram reunidas as visões dos professores sobre as exigências da prática quanto ao planejamento, ao trabalho, aos conhecimentos artísticos e às metodologias, e a relação

\footnotetext{
${ }^{14}$ Subtil (2016a) aprofunda estudos sobre as DCE - Arte, em sua proposta de conhecimentos e metodologias para o ensino de Arte na Educação Básica.
}

Práxis Educativa, Ponta Grossa, p. 897-916, v. 11, n. 3, set./dez. 2016 Disponível em: <http://www.revistas2.uepg.br/index.php/praxiseducativa $>$ 
com a gestão da escola. O que prevalece nos depoimentos são "[...] os limites do que é possivel fazer dadas as condições" (Egressos em geral).

\section{Planejamento - a dimensão teleológica da práxis}

O planejamento é anual, feito a partir das DCE - Arte (PARANÁ, 2009) para duas aulas semanais, em sua maior parte divididas em 4 bimestres contemplando Dança, Teatro, Música e Artes Visuais no Ensino Fundamental e no Ensino Médio. Neste último nível, o plano é elaborado em cima dos conteúdos do PSS (processo seletivo seriado que contempla conteúdos gerais de Arte). No caso específico do Ensino Médio, importa destacar que há casos de escolas em que a disciplina de Arte não é contemplada nos três anos, ficando relegada a dois ou, até mesmo, apenas um ano dessa etapa.

Os egressos, de modo geral, referem-se ao planejamento como dado e estabelecido a priori juntamente à equipe técnico-pedagógica: "[...] o planejamento é anual e todas as áreas devem ser contempladas, todos os professores envolvidos opinam mas têm que seguir o plano" (Egresso de AV). No entanto, alguns ressalvam que o plano para o Ensino Médio "[...] é elaborado em cima dos conteúdos do PSS (ênfase na História da Arte) "[...] e aprofunda mais música e artes visuais "[...] pois os alunos precisam mais disso". A dança fica para o pessoal de EF” (Egressos de Música e AV).

Para um professor de Música, o planejamento "[...] é muito difícil pela dúvida entre ficar na especificidade e atender às expectativas das DCE. Priorizo a área especifica [no caso a Música] explicando para os alunos o porquê". Ressalta-se que esse foi o único dos respondentes que questionou explicitamente o planejamento bimestral tal como proposto.

No "planejamento anual", detecta-se o problema da burocratização da gestão da prática artística na escola. Entende-se que a práxis supõe teleologia - conhecimento e prefiguração de um resultado que pode sofrer intervenientes no desenvolvimento da ação (VÁZQUEZ, 1986) -, assim, ela não pode ser engessada em uma perspectiva positivista meramente de previsão para a ação. A educação estética supõe o envolvimento da singularidade na efetivação da sua genericidade (universal). Isso significa que os processos/produtos artísticos, seja no fruir seja no produzir tanto individual quanto coletivamente, supõem o aporte da histórica, da técnica e da sensibilidade, para além de um rol de atividades que servem aos objetivos imediatistas da educação escolar tal como proposto na abordagem da pedagogia das competências.

\section{Conteúdos e metodologias priorizados - forma e conteúdo na Arte e no ensino}

Discutir metodologias e conteúdos de Arte e a respectiva "aplicabilidade" na docência supõe analisar a particularidade ontológica e histórica da produção artística. Para Lukács (1970, p. 170), “[...] a forma artística é a forma específica e particular daquela determinada matéria que constitui o conteúdo de uma obra". Magalhães (2015, p. 75) comenta que isso implica que "[...] um determinado autor, mantendo o mesmo ponto de vista estilístico crie uma forma específica para cada uma de suas obras. Do mesmo modo, um único conteúdo apresentará formas diferenciadas, dependendo da autoria sobre ele”. Lukács (1970) diz que há

[...] impossibilidade de aplicar universalmente uma determinada técnica artística, ou mesmo, simplesmente de recebê-la pronta e acabada sem fazer nenhuma modificação. Isso acontece é óbvio, porque a forma artística é a forma de um conteúdo determinado; por isso, não permite uma generalização fora daquela particularidade que ela estabelece em cada oportunidade. (LUKÁCS, 1970, p. 175).

Práxis Educativa, Ponta Grossa, p. 897-916, v. 11, n. 3, set./dez. 2016 Disponível em: <http://www.revistas2.uepg.br/index.php/praxiseducativa> 
Assim como há indissociabilidade entre forma e conteúdo artístico, isso deveria ser transposto para a metodologia do ensino de Arte para além de uma visão protocolar de conteúdos por bimestre, ou de saberes isolados - notação, harmonia, elementos constituidores, etc. O princípio metodológico seria a explicitação da universalidade da Arte e da sua particularidade em cada produto musical datado e situado (música da mídia, música folclórica, instrumentos, etc. em seu contexto e função histórica). O fundamento dessa metodologia seria averiguar qual papel esse conteúdo/forma específico de cada manifestação desempenha e desempenhou no processo de humanização e em que medida pode-se apropriar ainda hoje desses objetos artísticos e avançar no processo de educação estética com os alunos.

Nas manifestações, aparece o que é efetivamente trabalhado pelos professores de Música que demonstram esforço para colocar em ação os conhecimentos específicos. Eliminando-se as repetições, são esses os conteúdos denominados pelos egressos: noções básicas de teoria, percep̧̧ão, ritmo e percussão corporal, apreciação musical, exercícios rítmicos, videoclipes e alguns termos teóricos, jogos, instrumentos musicais, a "base da música" [não explicitou], história, prática com instrumentos (percussão e flauta), audição ativa, canto, parâmetros do som, composição. Uma egressa da Música diz: "Os conteúdos que trabalho giram em torno da história da música brasileira e músicas da mídia fazendo paralelos entre elas e com os elementos formadores do som". Essa professora sintetiza uma prática geral: "Abordo as outras áreas através da história porque acho difícil fazer práticas com áreas que não são minha especificidade".

Esta é sem dúvida uma estratégia para contornar o problema da falta de conhecimento dos conteúdos das outras áreas e aponta para uma metodologia mais expositiva por parte do professor, contemplando mais leitura e estudos teóricos com menos produção e envolvimento cognitivo intuitivo por parte dos alunos. Cabe descrever que, nas DCE, o encaminhamento metodológico apresenta o princípio da unidade de três momentos do planejamento das aulas de Arte:

Teorizar: fundamenta a possibilidade ao aluno que percebe e aproprie a obra artística bem como desenvolva um trabalho artístico para formar conceitos artísticos; Sentir e perceber: são as formas de apreciação, fruição, leitura e acesso à obra de arte; Trabalho artístico: é a prática criativa, o exercício com os elementos que compõe a obra de arte. (PARANÁ, 2009, p. 70).

Detectam-se nas manifestações, de modo geral, conhecimentos sobre os conteúdos e a metodologia proposta nas DCE que, provavelmente, são abordados nas reuniões anuais para planejamento. Infere-se, também, o esforço em adequar-se a essas formulações, certamente sem a devida avaliação crítica desses postulados. O que não fica claro é qual o resultado que objetivamente esperam e qual a função com que dotam o ensino de Arte no segmento em que trabalham.

Uma constatação evidente é que as escolas, ao nomearem o "ensino de Arte", referem-se prioritariamente às Artes Visuais, e essa prioridade parece ser parte de uma tradição escolar (SUBTIL, 2014). Desse modo, muitos professores de Música capitulam e uma fala é representativa: "Artes Visuais são mais fáceis de trabalhar do que os outros conteńdos. Trabalbo com o livro da Graça Proença [História das Artes Visuais]" (Egressa de Música). Essa mesma professora, que diz encontrar dificuldades para trabalhar com o conhecimento específico de cada área, continua: "De teatro faço improvisação, mimica, novela, e dança não trabalho".

Sintetizando, nota-se que há uma espécie de consenso dos egressos da Música em lidar com as outras áreas por meio da história da Arte, leitura de imagens, desenho, textos, vídeos, atividades dirigidas, atividade em grupo. Eles enfatizam a parte teórica por intermédio de exposição oral e as práticas acontecendo "dependendo do assunto", ou seja, o conteúdo relacionado para cada bimestre. Uma constatação decorrente dessas falas é que, em certa medida, a 
metodologia do ensino de Arte, especialmente no segundo grau, tem contemplado a "teoria" por meio de "aulas expositivas" (textos) e apreciações/audiências (imagens, músicas e vídeos), dadas as condições físicas e pedagógicas do ambiente escolar.

Quanto às considerações gerais sobre conteúdos e métodos em Arte na escola, pode-se completar com algumas ideias reveladas nas linhas e nas entrelinhas dos escritos. Apenas um dos pesquisados afirma a música em sua especificidade e diz ser muito difícil trabalhar as expectativas das DCE - Arte em Música, Teatro, Artes Visuais e Artes Plásticas (PARANÁ, 2009), porque fica em dúvida sobre o que trabalhar em meio a tantos conteúdos. Segundo ele: "Priorizo o conhecimento musical para os alunos e explico a eles o porquê dessa escolha” (Egresso de Música). Esse mesmo professor diz que sente falta de livro didático.

Importante destacar que nem todos questionam as DCE - Arte (PARANÁ, 2009) e a forma de planejamento nas quatro áreas. Alguns mencionaram a obrigatoriedade da Música por força de lei, mas não rejeitam categoricamente o trabalho com conhecimentos que não fizeram parte de sua formação. Um egresso de AV afirma que é "[...] viável e importante trabalhar com os eixos que atravessam as DCE, embora as dificuldades sejam inerentes à falta de conbecimentos das outras áreas". Ele faz referência ao projeto "Mais educação" como possibilidade de uma atuação ampla com Arte. Nessa perspectiva, alguns professores de Música manifestam-se favoráveis a projetos de caráter governamental - por exemplo, ensino de flauta doce - como uma forma de melhorar e "facilitar" o trabalho na escola. Ressalta-se, entretanto, que essas atividades são habitualmente trabalhadas em contraturno e não se destinam a todos os alunos.

\section{Requerimentos da escola e dos alunos para a atividade docente}

Uma questão recorrente é que a função da Arte, em geral, e da Música, em particular, historicamente, tem sido dirigida mais à diversão e menos ao conhecimento. Isso se revela em uma fala de um egresso de Música que afirma: "Os alunos querem trabalhar os conteúdos que os agradam”. Isso significa, em Música, replicar o que já vem da mídia. Pelo que se observa nas manifestações, há resistências por parte dos adolescentes em aprofundar conhecimentos musicais ${ }^{15}$. Embora esse professor use a estratégia de "contemplar o gosto deles", ele reconhece que "tem quer ir além no conhecimento" porque, contraditoriamente, apesar dessa resistência em aprender música na escola, "eles não vivem sem ela".

Professores de Artes Visuais queixam-se de que a disciplina é secundária no currículo e confundida com educação artística e artesanato e colocam a gestão também como responsável: "É necessário conscientizar não só os alunos, mas toda gestão escolar da importância do ensino de Arte, no desenvolvimento de competências como forma de expressão, comunicaşão e elemento transformador que o conhecimento em artes proporciona". Outra manifestação diz: "Muitos dos alunos, veem até hoje a aula de Arte como a aula para descontrair, desenhar e ficar tranquilo".

São questionadas as velhas práticas como "desenhar, pintar, fažr dobradura", sem uma visão clara de que conteúdos essas práticas podem abordar, decorrentes de uma tradição estabelecida na escola de "Arte como diversão e relaxamento" (Egressa de AV). Ela acrescenta: "Os alunos ainda não perceberam a necessidade da disciplina de Arte na escola". A egressa faz referência às diferenças entre a realidade da escola pública e particular quanto a isso:

Na rede particular de ensino a visão é mais diferenciada, pois os alunos prestam concursos (PSS) e assim apresentam um interesse maior por todas as áreas de ensino

\footnotetext{
${ }^{15}$ Sebben (2009) faz essa constatação em sua pesquisa de mestrado.
}

Práxis Educativa, Ponta Grossa, p. 897-916, v. 11, n. 3, set./dez. 2016 Disponível em: <http://www.revistas2.uepg.br/index.php/praxiseducativa $>$ 
Possibilidades e limites da formação do professor de Arte e da educação artística escolar...

da Arte bem como produzem e compreendem melhor sua importância. Os alunos das escolas públicas que eu trabalho querem criar, mas muitas vezes temos que podar essa criação, essa necessidade artística deles devido ao tempo, conteúdos, mudanças de calendários, comemorações. (Egressa de AV).

Essa manifestação mostra a prática que se mantém nas escolas públicas do uso da Arte como "comemoração" e o caráter pragmático da escola particular que, dada a clientela "interessada", aproveita todos os conhecimentos em função de sua utilidade para a ascensão profissional (vestibular). Um egresso de AV diz que a disciplina está sendo mais valorizada dentro da sua escola, mas acredita que isso é relativo porque "haveria necessidade de dispor de materiais apropriados para fazer as práticas e as produções artísticas". Outros egressos de AV afirmam que recebem apoio da equipe pedagógica quanto a recursos e materiais (já foi mencionada a preferência pelas atividades de AV na escola). No entanto, ressentem-se da falta de sala ambiente e laboratório. Quanto aos professores de Música, de modo geral, a queixa é quanto ao desinteresse dos alunos. Há também uma visão de que:

Arte é bom porque ajuda os alunos nas outras disciplinas, como se a Arte não fosse
um fim em si mesma. Dessa forma, se a própria escola tem dificuldade em perceber a
Arte como parte integral, importante e necessária do currículo, consequentemente os
alunos reproduzem essa dificuldade, portanto, muitas vezes, as suas reaçoes são de
descaso. Assim, eles não se empenham nas atividades, não entregam trabalhos e
reproduzem a máxima: "Arte não reprova". A necessidade urgente, a meu ver, seria
distanciar a polivalência da disciplina. (Egressa de Música).

Note-se que não fica muito clara, nessa visão, em quais aspectos a Arte poderia se diferenciar "das outras disciplinas" com a exigência de "reprovação". Alguns se manifestam no sentido de que, se há um estigma de disciplina secundária, isso está mudando gradativamente com a inclusão dos conhecimentos artísticos em concursos vestibulares e provas como o Exame Nacional do Ensino Médio (ENEM) e o Processo Seletivo Simplificado (PSS). Como mostrar-seá adiante, há um facilitador/complicador da inclusão da Arte na escola que é a relação com a gestão.

\section{Requerimentos dos gestores para trabalho com Arte na escola}

É importante destacar o papel da gestão escolar (equipe técnico-pedagógica) na efetivação (ou não) da prática artística pelas concepções de ensino de Arte, trabalho artístico, disciplina e organização da sala de aula e, especialmente, pelas exigências estabelecidas para os professores de Arte/Música no espaço escolar. ${ }^{16}$

Paro (2010, p. 765) considera a administração (gestão) como “[...] mediação para a realização de fins". O autor, mais adiante, complementa: "[...] assim parece óbvio que, quanto maior a relevância dos objetivos, maior a importância das mediações para conseguir realizá-los". Aliando essa visão ao conceito de planejamento inerente à práxis, pode-se dizer como Vázquez (1986, p. 187) que "[...] a atividade propriamente humana só se verifica quando os atos dirigidos a um objeto para transformá-lo se iniciam com um resultado ideal, ou finalidade, e terminam com um resultado ou produto efetivo, real". Isso significa, em primeiro lugar, que deve existir claramente (idealmente) um fim a ser atingido, no caso a educação artística dos alunos, e, em

\footnotetext{
16 Stori (2011) e Stori e Subtil (2014) analisam a gestão das DCE - Arte tanto em sua elaboração quanto em sua efetivação na escola. A pesquisa com gestores escolares mostra, de forma detalhada, o modo como são apropriadas as determinações legais para a Educação Artística na escola.
}

Práxis Educativa, Ponta Grossa, p. 897-916, v. 11, n. 3, set./dez. 2016 Disponível em: <http://www.revistas2.uepg.br/index.php/praxiseducativa $>$ 
segundo, que as mediações devem intervir de forma qualitativa, ancoradas no conhecimento para a efetivação da práxis como produção objetiva na/da realidade.

Os egressos, de modo geral, entendem que não há um real envolvimento da equipe técnico-pedagógica no sentido de apoio e de defesa do trabalho com Arte. Os professores de Música afirmam que a gestão apoia e dá suporte principalmente quando há algum "produto" ou resultado final como "Coral". Segundo um deles, em algumas escolas "[...] é possivel um bom diálogo para fažer apresentação, mas de maneira geral o professor nem é notado". A disciplina é vista às vezes como "[...] sem importância, embora haja aquisição de materiais para projetos quando bá interesse" (Egresso de Música). De certa forma, é uma prática de troca. Os professores atuam nos eventos e recebem apoio e material. Não há necessariamente um projeto de Arte na escola. Uma queixa que resume a percepção dos professores de Música é que "[...] os gestores não estão conscientes da especificidade da formação e exigem polivalência [...] é necessário conscientizá-los também” (Egresso de Música).

Outro depoimento que traduz o tradicional conflito entre gestores e professores de Música é quanto ao trabalho com os elementos básicos - som e ritmo - que interferem no ambiente escolar: "Normalmente não participam e até reclamam do meu trabalho quando faço percussão ou ritmo por atrapalhar as outras áreas. Não há envolvimento, apenas a cobrança quanto ao PTD (Plano de Trabalho Docente) e o dominio da turma" (Egressa de Música). Isso significa não fazer barulho e manter o controle dos alunos.

Os professores de Música afirmam que há consciência da obrigatoriedade da Música na escola, mas isso, de certa forma, não muda a situação porque não há condições físicas, materiais e humanas para dar conta disso. Nesse ponto, entra o papel do gestor quando está comprometido (ou não) com essa efetivação.

Um depoimento expressa a ideia de "culpabilidade" do professor pela condição da Arte na escola quando diz: "Cabe a nós professores mostrar a importância da Arte na escola, mostrar que a formação é importante, que não é qualquer professor que pode trabalhar a disciplina" (Egressa de Música). Dessa forma, ela isenta a gestão pelo encaminhamento inadequado. Uma professora de AV resume a demanda da maioria: "Desvincular a disciplina de Arte das atividades comemorativas, decoração do ambiente escolar, e incentivo à formação continuada dos docentes na ativa".

A exigência de trabalhar com as quatro áreas acarreta uma ação solitária e individual por formação continuada (e em serviço) na busca de conhecimentos, de livros, de técnicas, de vídeos, de exercícios (e algumas "receitas prontas") que auxiliem nessa tarefa. Nesse sentido, a gestão teria papel fundamental a partir da compreensão da função da Arte na formação dos alunos, em suprir as necessidades que isso acarreta na escola em termos de organização, espaços, materiais e formação dos professores.

$\mathrm{Na}$ verdade, a visão que no geral os gestores possuem, salvo exceções, historicamente como Arte na escola, é o resquício de práticas do canto orfeônico, atividades expressivas, artes plásticas (principalmente desenho), preferencialmente manifestadas em produtos como apresentações, comemorações e objetos decorativos. A Arte assim afirma-se como uma atividade secundária que deve preencher requisitos formais curriculares.

Nas manifestações em geral, percebe-se a subsunção dos professores a uma forma degradada de trabalho em função das necessidades inerentes à sobrevivência nesta sociedade. $\mathrm{O}$ contato direto com licenciandos professores e artistas da Música e das Artes Visuais permitiu afirmar a instabilidade financeira desses sujeitos (que, em sua gênese profissional, consideram-se 
artistas, instrumentistas, dada a incompatibilidade do capital à produção artística por seu valor inerentemente de uso e menos de troca). ${ }^{17}$

Ao discutir sobre os dilemas da prática docente dos professores de Arte/Música, Subtil (2015) denuncia que

[...] a exploração do trabalho docente também pelas horas excedentes, baixos salários, horários inconvenientes, salas lotadas, mas principalmente pela submissão à racionalidade capitalista que não permite efetivamente que a arte cumpra sua função humanizadora na formação dos nossos alunos, nas condições em que ela se insere na escola. (SUBTIL, 2015, p. 185).

\section{Para concluir: reflexões sobre as demandas da educação artística e os limites da atividade docente}

A Arte é conhecimento e manifestação da relação sensível do homem com a realidade, capaz de captar e refletir em profundidade a essência do real. O professor de Arte trabalha com duas dimensões do conhecimento humano: o sensível intuitivo e o inteligível reflexivo.

Não se pode dicotomizar essas dimensões considerando que a percepção corpóreosensível e a reflexão racional são a base do conhecimento tanto científico quanto artístico do ser social. A especificidade do ensino de Arte é o desenvolvimento da capacidade de sentir, perceber, conhecer o mundo e de expressar tal percepção nas diferentes manifestações: visuais, musicais, cinestésicas, teatrais etc. Nesse processo, realiza-se a vocação fundamental da educação escolar que, conforme Saviani (1991, p. 21), "[...] é o ato de produzir direta e intencionalmente, em cada indivíduo singular, a humanidade que é produzida histórica e coletivamente pelo conjunto dos homens". Entende-se que isso supõe identificar os conhecimentos e a cultura que devem ser assimilados e também os métodos mais adequados para atingir esses objetivos pelos alunos nos diferentes níveis escolares.

Assim, é necessário ressaltar que o saber pedagógico para o ensino de Arte deve contemplar conteúdos gerais do campo da Arte em sentido lato como produção humana e social, conhecimentos da especificidade das áreas artísticas, conhecimentos culturais do tempo e dos espaços onde se situam os alunos e, evidentemente, os saberes históricos, didáticos e pedagógicos que são próprios do fazer docente. Paro (2010, p. 772) diz que, para além de práticas meramente repassadoras de conhecimentos e informações, "[...] educar envolve uma relação política entre sujeitos empenhados na construção de personalidades". A peculiaridade do trabalho docente é o fato de que há uma "relação de convivência entre sujeitos" em que o aluno deve querer aprender, ou seja, estar mobilizado e motivado para isso e envolver sua personalidade colocando em ação outros elementos que o constituem: valores, crenças, intuições, emoções, visão de mundo (PARO, 2010).

Como pôde-se constatar na fala dos professores, na escola prevalece a ideia da Arte como atividade secundária, ainda ligada a eventos e a datas comemorativas. A dimensão educativa e a estética acabam submetidas a essas atividades em detrimento da humanização que decorre da relação de convivência entre sujeitos mobilizados para fazer e apreciar Arte.

\footnotetext{
17 Pesquisa em andamento com mais de 60 alunos das Licenciaturas de Música da UEPG, EMBAP e Universidade Estadual de Maringá (UEM) mostra até o momento que a grande maioria não pretende atuar como professor na Educação Básica, mas sim no campo da Música como artista (SUBTIL, 2016b). De todo modo, constata-se, pelos dados do Núcleo Regional de Educação, que uma grande parte dos formandos participou em anos anteriores de concurso público para a docência, provavelmente pela segurança da remuneração fixa.
}

Práxis Educativa, Ponta Grossa, p. 897-916, v. 11, n. 3, set./dez. 2016 Disponível em: <http://www.revistas2.uepg.br/index.php/praxiseducativa $>$ 
Ao levar-se em conta as manifestações dos egressos, é possível deduzir que os aspectos pedagógicos e educativos necessários à sua formação, da Música em especial como foco principal deste levantamento, são pouco considerados como condição para o trabalho docente com os adolescentes e jovens da Educação Básica.

Outro dado significativo é a generalização da ideia de que o professor deve "buscar a própria formação" ou procurar resolver os problemas da prática que as Licenciaturas não enfocaram de forma individual, como compromisso e responsabilidade de cada um. Ora, essa é uma questão que deveria fazer parte dos debates sobre currículos dos cursos, sobre a legislação estadual - DCE - Arte (PARANÁ, 2009) - e especialmente sobre o papel dos gestores na implementação do ensino de Arte nas escolas, tendo em vista a particularidade legal. Mészáros (2005), ao refletir a respeito da educação, diz:

A educação, nesse sentido, é verdadeiramente uma educação continuada [...] como constituinte necessário de princípios de uma sociedade para além do capital, é inseparável da prática significativa da autogestão [...] no sentido de permitir um efetivo feedback dos indivíduos educacionalmente enriquecidos, com suas necessidades mudando corretamente e redefinidas de modo equitativo, para determinação global dos princípios orientadores e objetivos da sociedade. (MÉSZÁROS, 2005, p. 75).

A submissão do trabalho docente às demandas internas da escola não deve dispersar a possibilidade de ação dos sujeitos coletivos nas lutas sindicais e nos movimentos sociais, na busca por legitimidade profissional e social tendo em vista as dimensões contraditórias da própria realidade. Essa é uma perspectiva de construção identitária da profissão docente que não tem sido explorada na formação dos professores "em serviço", que se alienam na resolução dos problemas cotidianos, com exploração de "técnicas pedagógicas" de rápido retorno, mas que não constituem conhecimentos e reivindicações condizentes à construção de um estatuto profissional docente, em Arte especialmente.

Apregoa-se uma perspectiva dialética na formação das Licenciaturas que considere a universalidade, a particularidade e a singularidade inerentes ao campo artístico ${ }^{18}$. Os conteúdos gerais da Arte em sua ontologia decorrem da universalidade genérica mediada pela particularidade histórica e contextual e objetivada na singularidade das manifestações artísticas (Música, Teatro, Artes Visuais e Dança). Em muitos momentos da história da Arte, cada uma dessas áreas apresenta o que Lukács (1970) denomina o típico, o qual revela particularidades propriamente humanas que desvelam sentimentos, emoções e experiências estéticas nos homens singulares. ${ }^{19}$

Nesse sentido, pode-se validar as DCE quando trazem conhecimentos gerais do campo da Arte em eixos que criam tangenciamentos entre as áreas. Esse conhecimento deve fazer parte da formação do professor de Música, de Artes Visuais, de Dança e de Teatro para a Educação Básica. Considerando que cada área já tem garantida por legislação sua presença no currículo (AV, Teatro e Música, em especial), a potencialidade de uma formação estética para os alunos vêm da possibilidade de um trabalho conjunto, articulado, integrado entre esses professores (que, em uma perspectiva utópica, deveriam ser legitimados por concursos específicos) o que só ocorrerá se houver um conhecimento também integrado, articulado e tangenciado nas Licenciaturas. Isso sem fazer concessões à formação e às práticas aligeiradas e polivalentes, mas

\footnotetext{
${ }^{18}$ Lukács (1970, p. 157) define essas categorias como “[...] leis universais da estética em geral, leis concretamente particulares do gênero, diferenciação histórica dos gêneros (estilos MJ), configuração individual das obras de arte singulares [...]".

19 Aqui, entendemos as potencialidades de formação estética como compreensão da "[...] dialética do real que, a partir das aspirações particulares dos homens singulares e dos grupos, desenvolve a universalidade das modificações históricas das formações sociais que se sucedem” (LUKÁCS, 1970, p. 45).
}

Práxis Educativa, Ponta Grossa, p. 897-916, v. 11, n. 3, set./dez. 2016 Disponível em: <http://www.revistas2.uepg.br/index.php/praxiseducativa> 
afirmando peremptoriamente a especificidade de cada área que supõe sujeitos com uma préformação instrumental e teórica no caso da música (anterior ao ingresso na licenciatura), que o encaminha para um determinado trabalho.

Dito isso, nega-se as DCE na obrigatoriedade de um planejamento protocolar com cada bimestre enfocando artificialmente e de forma reduzida os conteúdos das linguagens artísticas. Apregoa-se a gestão de uma proposta baseada no conhecimento, na técnica, na fruição, que pode, em alguns momentos, até integrar-se em uma totalidade (peças teatrais, conjuntos vocais e instrumentais, exposições de Arte, etc.).

Por fim, considera-se que formação e atuação docente são momentos da práxis social que não se dissociam. Um professor não se "forma" apenas na graduação ou somente na prática cotidiana. As necessidades formativas do professor de Arte/Música são complexas, dadas as fragilidades dos currículos das Licenciaturas em Arte, especialmente de Música, no que tange à compreensão abalizada sobre o campo conceitual da Arte, sua função na sociedade e às características próprias da profissão docente no interior da escola. Além disso, entende-se que a prática social é o ponto de partida e de chegada tanto da formação docente quanto da educação escolar. É nela que se deve buscar os fundamentos das necessidades humanas dos alunos e dos pares com os quais se divide as possibilidades e os limites da profissão docente, tendo em vista a necessidade de superação da sociedade tal como se apresenta nestes tempos.

\section{Referências}

BRASIL. Lei $\mathrm{n}^{\circ}$ 11.769, de 18 de agosto de 2008. Altera a Lei $\mathrm{n}^{\circ}$ 9.394, de 20 de dezembro de 1996, Lei de Diretrizes e Bases da Educação, para dispor sobre a obrigatoriedade do ensino de Música na educação básica. Diário Oficial [da] República Federativa do Brasil, Poder Legislativo, Brasília, DF, 19 ago. 2008. Seção 1, n 159, p. 1.

LESSA, S. Mundo dos homens: trabalho e ser social. 3. ed. São Paulo: Instituto Lukács, 2012.

LUKÁCS, G. Introdução a uma estética marxista. 2. ed. Rio de Janeiro: Civilização Brasileira, 1970.

MAGAlHÃES, B. A particularidade em Vidas Secas, de Graciliano Ramos. 2. ed. São Paulo: Instituto Lukács, 2015.

MARON NETO, E. As diretrizes curriculares nacionais para os cursos de graduação em Música e o projeto pedagógico do curso superior de instrumentos da EMBAP: movimentos de autonomia e adaptação. 2012. 129 f. Dissertação (Mestrado em Educação) Universidade Federal do Paraná, Curitiba, 2012.

MARX, K. O capital - Tomo I. São Paulo: Abril Cultural, 1983. v. I.

MATEIRO, T. Uma análise de projetos pedagógicos de Licenciatura em Música. Revista da ABEM, Porto Alegre, v. 22, p. 57-66, set. 2009.

MÉSZÁROS, I. A educação para além do capital. São Paulo: Boitempo, 2005.

MORAES, M. M. de. Recuo da teoria: dilemas na pesquisa em educação. Revista Portuguesa de Educação, Braga, v. 14, n. 1, p. 7-25, 2001.

Práxis Educativa, Ponta Grossa, p. 897-916, v. 11, n. 3, set./dez. 2016 Disponível em: <http://www.revistas2.uepg.br/index.php/praxiseducativa $>$ 
PARANÁ. Diretrizes Curriculares da Educação Básica - Arte. Curitiba: SEED, 2009. Disponível em: <www.diaadiaeducacao.pr.gov.br>. Acesso em: 10 fev. 2016.

PARO, V. H. A educação, a política e a administração: reflexões sobre a prática do diretor de escola. Educação e Pesquisa, São Paulo, v. 36, n. 3, p. 763-778, set./dez. 2010.

PEREIRA, M. V. M. Habitus Conservatorial: do conceito a uma agenda de pesquisa. In: CONGRESSO DA ANPPOM, 23., 2013, Natal. Anais... Natal: ANPPOM, 2013. p. 1-8.

SAVIANI, D. Pedagogia histórico-crítica: primeiras aproximações. São Paulo: Cortez; Autores Associados, 1991.

SEBBEN, E. E. Concepções e práticas de música na escola na visão de alunos de $8^{\mathrm{a}}$ série do Ensino Fundamental: as contradições entre o legal e o real. 2009. 167 f. Dissertação (Mestrado em Educação) - Universidade Estadual de Ponta Grossa, Ponta Grossa, 2009.

STORI, R. As Diretrizes Curriculares de Arte do Estado do Paraná: uma análise dos fundamentos e da gestão do ensino de Música em Ponta Grossa/PR (2003-2010). 2011. 190 f. Dissertação (Mestrado em Educação) - Universidade Estadual de Ponta Grossa, Ponta Grossa, 2011.

STORI, R.; SUBTIL, M. J. Diretrizes Curriculares do Estado do Paraná: um panorama sobre o ensino de Arte a partir do processo de construção e implementação da proposta. Jornal de Políticas Educacionais, Curitiba, n. 15, p. 72-83, jan./jun. 2014. DOI: 10.5380/jpe.v8115.36251

SUBTIL, M. J. D. A prática como proposta de integração entre conhecimentos acadêmicos e realidade profissional/cultural para a formação de docentes em Artes. In: ENCONTRO ANUAL DA ASSOCIAÇÃO BRASILEIRA DE EDUCAÇÃO MUSICAL - ABEM, 12., 2003, Florianópolis. Anais... Florianópolis: CEARTE/UDESC, 2003. p. 1-7.

SUBTIL, M. J. D. Licenciatura em Música: a construção de uma proposta curricular. In: ENCONTRO ANUAL DA ASSOCIAÇÃO BRASILEIRA DE EDUCAÇÃO MUSICAL ABEM, 13., 2004, Rio de Janeiro. Anais... Rio de Janeiro: UNIRIO, 2004. p. 786-793.

SUBTIL, M. J. D. Formação de professores de Artes: reflexões sobre a inserção dos acadêmicos nos espaços profissionais. Revista Diálogo Educacional, Curitiba, v. 9, n. 27, p. 317-333, maio/ago. 2009.

SUBTIL, M. J. D. Reflexões sobre formação de professores: expectativas e pré-formação de licenciandos em Música e Artes Visuais. Cadernos de Educação, Pelotas, v. 20, n. 40, p. 79-94, out./dez. 2011.

SUBTIL, M. J. D. Licenciatura em Música: dilemas da formação docente frente às demandas da prática escolar. In: CONGRESSO INTERNACIONAL DA FEDERAÇÃO DE ARTE/EDUCADORES DO BRASIL, 2.; CONGRESSO NACIONAL DA FEDERAÇÃO DE ARTE/EDUCADORES DO BRASIL, 24., 2014, Ponta Grossa. Anais... Ponta Grossa: UEPG, 2014. p. 1-15. 
SUBTIL, M. J. D. Licenciatura em Música: dilemas da formação docente frente às demandas da prática escolar. Cadernos de Pesquisa: Pensamento Educacional, Curitiba, v. 10, n. 24, p. 168188 jan./abr. 2015.

SUBTIL, M. J. D. Conhecimentos e metodologias para o ensino de Arte: recortes históricos sobre a lei no 5692/71 e sobre as diretrizes curriculares do estado do Paraná/2009. Educação em Análise, Londrina, v. 1, n. 1, p. 45-66, jan./jul. 2016 a.

SUBTIL, M. J. D. Projeto de pesquisa: Pré-formação e expectativas de licenciandos de Artes Visuais e Música na perspectiva de atuação na Educação Básica no estado do Paraná. 2016b.

TREVISAN, A. L. Filosofia da Educação e formação de professores no velho dilema entre teoria e prática. Educar em Revista, Curitiba, n. 42, p. 195-212, out./dez. 2011.

TROJAN, R. Estética pós-moderna ou estetização do real? Impactos no trabalho e na educação. In: SCHLESENER, A. H.; MASSON, G.; SUBTIL, M. J. (Orgs.). Marxismo(s) e educação. Ponta Grossa: UEPG, 2016. p. 145-172. (No prelo).

UEPG. Universidade Estadual de Ponta Grossa. Projeto Político Pedagógico. Curso de Licenciatura em Música. Ponta Grossa, 2003.

UEPG. Universidade Estadual de Ponta Grossa. Projeto Político Pedagógico. Curso de Licenciatura em Música. Ponta Grossa, 2008.

VÁZQUEZ, A. S. As ideias estéticas de Marx. 2. ed. Rio de Janeiro: Paz e Terra, 1978.

VÁZQUEZ, A. S. Filosofia da práxis. 3. ed. Rio de Janeiro: Paz e Terra, 1986.

Recebido em 10/03/2016

Versão corrigida recebida em 04/07/2016

Aceito em 15/07/2016

Práxis Educativa, Ponta Grossa, p. 897-916, v. 11, n. 3, set./dez. 2016 Disponível em: <http://www.revistas2.uepg.br/index.php/praxiseducativa $>$ 